\title{
EVALUATION OF PSYCHO-SOCIAL FACTORS OF FEAR
}

\author{
Natia Archvadze \\ PhD Student, \\ Georgian Technical University
}

\begin{abstract}
Fear is part of the life and existence of any culture or individual. Over the years, the object of fear in a society and the strategies to combat it may change, but the expectation that people can be completely free from fear is simply an utopia. Different branches of psychology always tried to find distinguished explanations for the methods of originating and overcoming fear, although the fact is one, fear arises where there is a lack of individual's personal maturity. When a person avoids every new life experience and does not try to move to a new stage of growth, it all accumulates in him/her in the form of fear and the individual experiences developmental fixation.

It is also interesting to talk about the differences that exist between fear and anxiety, as these two emotions are often interrelated. If we refer to Barlow, fear differs from anxiety in that, fear is present-oriented and relatively certain, rather than future-oriented and relatively uncertain. Uncertainty not only increases anxiety levels, but is also responsible for a person's various mental disorders.

That is why, in the current situation in the world, when the Covid-19 pandemic affected the life of each individual, it is important to focus on the fear of the unknown situation caused by uncertainty. Usually, people want to control the present because with this they also want to take control over the future. In order to know what we are afraid of; it is necessary for a person to have insight by approaching the problem with consciousness and asking the questions to himself/herself. People in general have tendency to imagine a harsh scenario of the expected consequences of the future, which in many cases is completely far from the reality. It is fact that in case of having ,apocalyptic" thoughts it becomes impossible to deal with fear. In the end, those who fearlessly ,approach" this mentioned unpleasant emotion win the battle of overcoming fear.
\end{abstract}

Keywords: Fear, Anxiety, Fear of the Unknown Situation, Pandemic, Covid-19.

\section{Introduction}

The article below forms a systematic representation of fear, its expressive emotion, and the cognitive processes that are permanently ongoing in the human mind at the conscious or subconscious level. From many types of fear, the factor of uncertainty plays an increasingly important role today. Accelerating the rhythm of life, globalization, the growing flow of different content and non-systemic, including negative information, put a serious test on human psychological resilience. Therefore, establishing the correlation of events and processes associated with fear with people's reactions, with the processes going on in their consciousness, is the main goal of the article.

Even in ancient time, the subject of fear was a field of interest for philosophers, although by this time their explanation of fear was more general in nature and did not really help individuals personally.

For the last century, fear has been considered as „Newcomer" for empirical psychology. Despite his ,pioneer" status, psychoanalysis ${ }^{1}$ with its profound psychological approaches, behaviorism with its stimulus-response

${ }^{1}$ S. Freud, „Über die Berechtigung, von der Neurasthenie einen bestimmten Symptomkomplex als „Angstneurose“ abzutrennen“, Studienausgabe Frankfurt/M.: S. Fischer 1971, S.27-47. 
analysis, as well as cognitive psychology, ${ }^{2}$ which played an important role in psychology in the late 1960s, pay great attention to the topic of fear. It is also important cognitive transactional theory of Richard Lazarus, which has gained considerable popularity in recent decades. According to this theory, emotions arise as a result of a cognitive assessment process. Not the critical situation itself originates the feeling but the subjective interpretation of the fact. According to this theory, fear is a specific, cognitively transmitted emotion during a stress episode.

Modern research of fear is focused on answering questions such as the impact of fear on people's health, the role of fear in treatment of mental disorders, in originating of aggressive behavior, and more.

$\mathrm{Krohne}^{3}$ describes fear as ,an affective state of the body when there is a feeling of tension, danger, and anxiety due to increased activity of the autonomic nervous system and self-absorption caused by excitement."

Fear is generally a part of human life that accompanies a person from birth to death. The history of mankind invents new methods to overcome or avoid fear, however it would be illusion if we believe that a human being can live without fear. Fear is part of an individual's existence and we can only develop defense mechanisms against it: Courage, confidence, power, hope, faith and love are those things that help us in this. The methods that promise complete relief from fear should be viewed with skepticism because they do not take into the consideration the reality of being human and create illusory expectations.

Fear exists regardless of the culture and level of development of the community. It means that as time goes by, epochs change but the feeling of the mentioned emotion in a person remains unchanged. The only thing that can be changed is the object of fear, against which different measures and means are used. Today we are no longer afraid of lightning and thunderstorm, solar and lunar eclipses, because we know that this is not the end of the world. However, we have fears that early cultures did not know about, such as the fear of bacteria and new diseases.

As for the methods of overcoming fear, if in the past people asked for help to those who would cast a spell on them in order to cure them, now there are medicines that assist a person to overcome the emotion. Nowadays one of the most effective methods of dealing with fear is also psychotherapy.

Fear affects different people distinguishably and therefore the reaction of a frightened person can also be different. In one case the individual defense mechanism may become more active after the fear and start taking active action to overcome or avoid it, while in the other case the experienced fear may cause the complete inability of the person and freeze him/her in one place.

\section{Freud's two theories of fear}

There are cases when fear arises situationally, which Freud refers to as signal fear. Signal fear as an alarm signal has a protective reaction in dangerous situations such as escape or defense. If there would not exist such emotion, people would not have avoided various dangerous situations and their lives would often have been in danger.

Fear in general is a signal and warning of any danger and a specific impulse is needed to overcome it. How a person copes with fear shows the level of his development, and each overcome fear contributes to the inner maturity of a person. If an individual is unable to cope with fear, he experiences stagnation, which prevents him from moving to the next stage of his personal development.

Fear arises in the place from which a person has not yet grown up. Any development, the stage of maturity is related to fear, because it leads to something new, to the hitherto unknown, to internal and external situations in which we have never been before, which we have never experienced. Every age consists of maturity stage

\footnotetext{
${ }^{2}$ M. Eysenck, „Cognitive functioning and anxiety”, Psychological Research, 1987, pp. 189-195.

${ }^{3}$ H. Krohne, „Repressive emotional discreteness after failure”, Journal of Personality and Social Psychology,1996, pp.1318-1326.
} 
and certain fears associated with it. To pass any stage of development successfully, it is necessary to overcome the fears connected with this stage.

If we think about the small steps a child tries to independently take when he or she first time lets go his or her mother's hand, he or she will have fear to walk independently, which must be overcome. Fear accompanies first time entering school, starting a family, getting old, thinking about death, and so on. All these fears are an integral part of our lives. Each such step is like crossing the border and requires from us giving up the familiar situation and take a step towards something new, unknown.

According to Freud, if a person tries to suppress and expel fear, it can also become a major cause of neurosis. The particular interest to the founder of psychoanalysis was the fear that comes from the taboo of incest and the Oedipus complex. This fear arises, as he describes in „Totem und Taboo ${ }^{“ 4}$, from the foundations of cultural development and its society.

In this paper, Freud proposed a new theory of the origin of human society. He expressed the view that members of one tribe worshiped plants and things as a common totem, united by a common kind of religion. Life in this society is limited by the Taboo, which he explained by the prohibition of killing a father. In his later work, Freud developed a definition of classical fear. All schools have since contributed to the understanding of fear, its origins, manifestation and elaboration.

In the literature there are separated Freud's two theories of fear. They can be formally called the „first and second fear" theory. The first is the theory of neuropsychological fear and the second is the theory of psychological fear.

In the first theory of fear, Freud concentrates on the neurosis of fear. According to him the cause of fear neurosis is the blocking of sexual tension. For him, the fear neurosis is formed by a sequence of certain processes: 1. There is a sexual impulse; 2. Sexual impulse is blocked. 3. Excitement intensity increases 5. Accumulated excitement is released in the form of a fear reaction.

According to Freud, fear is an affective state with psychological, behavioral-motor and subjective components, which arises when an individual feels incapable of coping with specific tasks with appropriate reactions.

More than 30 years after the first theory of fear was formulated, the psychoanalytic concept has changed dramatically, concentrating on expulsion as a determinant of behavior becomes less important, and it has been replaced by the central concept of mental conflict. Behind the term „conflict“ there are meant mental forces that oppose each other. Such forces are able to awaken the „unconscious" fantasies of childhood.

To explain this conflict, Freud proposed the idea of mental structure in terms of three "mental instances" which he called „Id", „Ego" and „Superego".

The second theory of fear is often referred to as the „Signal Theory “. In this case Fear is defined as a signal of danger for Ego. Which means the cognitive (behavioral) signal of a person, through which danger can be avoided.

Fear of reality arises when the „Ego "realizes everything that is happening in the environment and expects to be harmed. A signal involves taking adequate action, such as fleeing or attacking.

Neurotic fear arises when the needs of the „Ego" come from the needs of the „Id", the fulfillment of which may put in danger the „Ego”.

The fears of moral or "Superego" arise when actions or thoughts do not coincide to the permissible norms of the "Superego" (established by the norms of parents, caregivers, or society). Such danger cannot be avoided by a person by fleeing, but he must bring his thoughts and actions in line with the norms allowed by "Superego"

\footnotetext{
${ }^{4}$ S. Freud, „Totem and Taboo” (1912-1913), The Standard Edition of the Complete Psychological Works of Sigmund Freud, London: Hogarth Press, Volume XIII.
} 


\section{Fear and anxiety}

The ancient Greeks had words such as mania, melancholy, hysteria, and paranoia (these Greek words are still used today), but they did not have a word for anxiety in their vocabulary. In modern Greek we find the word „anesuchia", the main meaning of which is ,not quiet" or ,not calm". The Romans in Ciciero times used the word ,anxietas", which meant a state of prolonged fear, and it was different from the word ,angor", which was used to describe a momentary state of strong fear.

In the Middle Ages and during the Renaissance, anxiety was associated with melancholy.

In ancient China it was suggested that there was some connection between human organs and emotions; For example, excessive anger was thought to be harmful to the liver, excessive happiness was associated with the heart. Fear damaged the kidneys, and boredom damaged the lungs.

In the early 18th century, the term anxiety was used in medical literature to refer to mental illness.

In the early 19th century, the focus shifted from mental health to somatic causes or possible psychological causes of mental illness.

In the beginning of 20th century, it was thought that the etiological factors of anxiety were hereditary or biological.

Later on, Carl Jasper spoke about the different nature of fear and anxiety. The various forms of anxiety that were rejected many years ago have once again become interesting what we now call social phobia.

According to Barlow, fear differs from anxiety in that fear is present-oriented and relatively certain rather than future-oriented and relatively uncertain. ${ }^{5}$

Anxiety in general is a complex emotional response that is similar to fear. Both are products of similar processes in the brain and cause similar psychological and behavioral reactions. However, fear and anxiety differ from each other in that fear is associated with a clear, existing, and identified threat, whereas anxiety is not related to an existing threat. In other words, we are scared when we are actually in danger and we experience anxiety when we feel some discomfort but at a particular moment we are not actually in danger.

Fear formation is influenced by various environmental factors, such as:

- A social environment, where traumatic moments provoke specific fears that a person may have for a lifetime;

- Observational learning, when observing another person takes place in a traumatic social environment. The person sees that another person has been injured in a particular situation and is afraid the same thing might happen to him or her;

- Transmitting information when, for example, frightened and socially anxious parents provide their children with information about the dangers of social situations;

- Upbringing, which is also important in shaping fears.

\section{Fear of the unknown situation}

Nowadays, when the whole world is involved in the fight against the Covid-19 pandemic, it is important to focus on the types of fears such as the fear of the unknown.

\footnotetext{
${ }^{5}$ D. Barlow, „Unraveling the mysteries of anxiety and its disorders from the perspective of emotion theory”, American Psychologist, 2000, pp.1247-1263.
} 
The first written source of fear of the unknown as a fundamental fear is found with Lovecraft in 1927: Fear is the oldest and most powerful emotion of mankind, and from a wide range of fears the fear of the unknown is special and distinctive. While all other fears require learning, realizing reality, or recalling information, fear of the unknown situation does not require prior study, on the contrary the reason for its origin is lack of information. ${ }^{6}$

Consequently, people's behaviors change depending on how they deal with different types of fears. There are individuals who are not disturbed by uncertainty and act risky. Such behavior may be due to their maturity and life experience. However, there are also other categories of individuals who respond to any new things with fear and anxiety.

If a person is afraid of spiders or snakes, this fear is natural because people learn that these species can harm their lives, although not all fears are based on such specific information. Some fears are based on what we do not know. Fear of the unknown situation is part of many other fears, anxieties and phobias. When a person does not have enough information to predict the future, it often becomes a cause of fear and anxiety.

In 2016, scientists studied the fear reflex of 160 adults related to sudden sounds and shocks. They found that individuals with social anxiety disorders and specific phobias were more likely to blink their eyes more often and sharply when they expected something foreign, unpleasant. Based on this, the scientists concluded that these individuals were more sensitive to the unknown situation. ${ }^{7}$

Also depressed people are more likely to experience anxiety than those who are not depressed. ${ }^{8}$

\section{Impact of the pandemic on the formation of fear}

The new Corona virus-2019 (Covid-19) can be said to have contributed to the formation of various fears of individuals. The pandemic caused by this virus has completely changed the daily life of people, which was caused by the quarantine imposed by governments and the demand for protection of social distance. It could be said that Covid-19 caused collective trauma because this event had a negative impact on the mental state of individuals. According to the results of one of the studies conducted with those infected with Covid-19, respondents showed strong emotional and behavioral reactions, such as fear, boredom, insomnia, anger. ${ }^{9}$

Also, according to a social study conducted after the outbreak of the respiratory virus ,SARS“, more than half of the participants in the study were diagnosed with a mental disorder.

It is noteworthy that during epidemics, individuals may exhibit poorly adaptive (maladaptive) behaviors if there are people around them who are considered to be a potential risk group. For example, according to one study, during the Ebola epidemic, which main area of distribution was Africa, individuals who did not live in Africa but in their neighborhood lived a foreigner from African descent, were exposed to Ebola-related anxiety. Outbreaks may also increase the risk of suicide. Uncertain situations and bad expectations can put a person of any age at risk. ${ }^{10}$ Older people, for example, may feel that in case of illness they could become burden for the family and this emotional state can lead them to suicide.

\footnotetext{
${ }^{6}$ N. Carleton, „The intolerance of uncertainty construct in the context of anxiety disorders: Theoretical and practical perspectives”. Expert Review of Neurotherapeutics, 2012, pp.937-947.

${ }^{7}$ S. Gorka, L. Lieberman, S. Shankman, K. Phan, ,Startle Potentiation to Uncertain Threat as a Psychophysiological Indicator of Fearbased Psychopathology: An Examination across Multiple Internalizing Disorders". https://www.ncbi.nlm.nih.gov/pmc/articles/PMC5215951/ [1. s. 27.09.2021].

${ }^{8}$ D. Jensen, J. Cohen, D. Mennin, D. Fresco, R. Heimberg, „Clarifying the Unique Associations among Intolerance of Uncertainty, Anxiety, and Depression”. https://www.ncbi.nlm.nih.gov/pmc/articles/PMC5045801/pdf/nihms-812743.pdf/ [1. s. 27.09.2021].

${ }^{9}$ C. Wang, R. Pan, X. Wan, Y. Tan, L. Xu, „Immediate psychological responses and associated factors during the initial stage of the 2019 coronavirus disease epidemic among the general population in China", Public Health, 2020 Mar 6.

${ }^{10}$ YT. Xiang, Y. Yang, W. Li, L. Zhang, Q. Zhang, T. Cheung, „Timely mental health care for the 2019 novel coronavirus outbreak is urgently needed", Lancet Psychiatry, 2020.
} 
Like other epidemics, the Covid-19 pandemic is associated with global anxiety and increased stress levels. The fear caused by the pandemic in the early stages of virus begin was so severe in some individuals that people committed suicide simply because they thought they were infected with Covid-19, although the autopsy showed that they were healthy. In general, the number of people at risk of mental health during epidemics exceeds the number of people actually infected. ${ }^{11}$

As for the Covid-19 fear, it can be divided into four main parts: body-related fear, fear related with loved ones, uncertainty, and action /inaction. This high level of uncertainty has led to radical changes in the daily lives of individuals. Most people do not want to know about the negative events that may occur in the future. Gigerenzer and Garcia-Retamero call this phenomenon the regret of knowledge. Individuals do not want to feel the threat of the future now, in the present, however they want to fully understand the current dangerous situation in order to take control over that situation. The current uncertain situation can therefore be considered as a significant risk factor for mental well-being. Unacceptability of an uncertain situation even leads to anxiety disorder, which ultimately has a negative impact on a person's well-being.

One of the leading roles in shaping public fears is also played by the media. Pandemic reports today are often overly intense, harsh, depressing, and toxic and fear of danger remains constantly relevant in the population.

What is needed to keep people mentally healthy? One of the main necessary conditions for this is the existence of social relations.

One of the social surveys conducted by University College in London, on March 21, 2020, referred to the mental health of individuals after Covid-19 lockdown in the UK. 70,000 respondents were involved in this study. They took part in a 10-minute online survey each week where they talked about their experiences with social distance events. In addition, telephone interviews were held.

It is noteworthy that the worst data on fear, depression, death thinking or self-harm and life satisfaction were shown by young people, as well as those below the average family income (less than 30,000 pounds) and those who said they had mental health problems. $8.5 \%$ of respondents often felt lonely before „Lockdown", after „Lockdown" this figure was $18.5 \%$. Young people between the ages of 18 and 29, single people and lowincome people were particularly lonely. ${ }^{12}$

\section{Fear coping techniques}

Fear is the conscious perception of an excited state that is painfully experienced. Because of this, people try to end this situation as soon as possible. Fear is therefore closely related to overcoming fear. In this regard, it is important to distinguish two approaches: One refers to the coping model of stress (Lazarus, 1966). According to this model there are distinguished: a) Appraisal-focused coping, b) Problem-focused coping, c) Emotionfocused coping.

Appraisal-focused coping involves logical analysis and a fresh assessment of the perceived source of fear. In problem-focused assessment, it is important to take active action to deal with the threat (for example, finding information on a social network and thus protecting oneself). Emotion-focused coping involves all attempts to reduce the fear response by managing emotion (breathing exercises, crying, and so on).

The second approach concerns Byrne's concept, which states that the style of coping with fear in all people fits into the personal dimension of the individual, which he called extrempole "repression" on one side and "sensitivity" on the other. The repressor tries to avoid dangerous information, while the sensitive ones prefer to use dangerous information. The one-dimensional model proposed by Byrne and the repression-sensitizationscale developed from it cause a variety of empirical and conceptual problems.

\footnotetext{
${ }^{11}$ S. Reardon, „Ebola's mental-health wounds linger in Africa”, Nature, 2015.

${ }^{12}$ F. Klein, ,Psychological health during lockdown “, https://link.springer.com/article/10.1007/s15005-020-1433-z/ [1. s. 27.09.2021].
} 
That is why nowadays the multidimensional model is often used in relation to overcome fear. The Krohn's model is particularly interesting in this respect. It distinguishes between two different strategies for overcoming fear: vigilance and cognitive avoidance. Individuals who have a high level of alertness in a dangerous situation try to choose a more cognitive and behavioral strategy aimed at finding information and controlling the situation. Individuals who do not address cognition about emotions, show a high degree of confusion and fear for threatening situations, which manifests itself in disorganized behavior.

\section{Conclusion}

In summary, fear is part of human existence. As long as a person is alive, he has to deal with different fears, this could be related to both developmental and different life fears. However, in case of successful overcoming of this emotion, the individual grows personally, becomes stronger, more self-confident and easily manages to adapt to different environments. There is no place on earth where a person feels completely protected. Every comfort zone has the potential to become uncomfortable in the future if the individual is not focused on action, development, overcoming his/her own fears. Eventually, those who begin to inspect themselves inwardly and realize what they are afraid of will be able to overcome their fears more effectively.

Fear in general is a universal phenomenon of human feeling. To overcome it, it is important for a person to use various psychological techniques that will help the individual to consciously overcome this mentioned emotion. Effective strategies to combat fear could be the following:

- First of all, the individual must admit to himself that he is afraid; When a person does not admit that his personality is overwhelmed with fear, that kind of attitude increases his fear and tension even more;

- It is necessary for a person to check in himself whether he perceives the danger excessively. People tend to paint a more horrible scenario of the future than this scenario might actually happen. A good way to check the situation is Byron Katie's „,The Work“", the technique of it is the following-in case one has fear, he/she should ask himself/herself four simple questions:

1. What I think, is true?

2. Can I absolutely be sure that this is true?

3. How do I react when this thought bothers me?

4. Who would I be without this thought?

- Relaxation exercises also help the individual to overcome fear. In this case the person should focus on his breath. This helps to stop concentrating on bad thoughts and reduces the symptoms of body tension.

- In addition, it is important that one develops a strategy against his/her fear. A person first must put in mind a plan how to overcome fear, and then try to implement it in reality. 


\section{BIBLIOGRAPHY}

1. Daniel Kwasi Ahorsu, Chung-Ying Lin, Vida Imani, Mohsen Saffari, Mark D. Griffiths, Amir H. Pakpour, „The Fear of COVID-19 Scale: development and initial validation". International Journal of Mental Health and Addiction 2020;

2. David H. Barlow, „Anxiety and its disorders: The nature and treatment of anxiety and panic” (2nd ed.). New York, NY: Guilford Press. 2002;

3. Harold Basowitz, Harold Persky, Sheldon J. Korchin, Grinker, R. Roy, Anxiety and stress. New York: McGraw-Hill. 1955 ;

4. Howard Berenbaum, Keith Bredemeier, Renee J. Thompson, „Intolerance of uncertainty: Exploring its dimensionality and associations with need for cognitive closure, psychopathology, and personality". Journal of Anxiety Disorders, 2008;

5. Paul A. Boelen, „Intolerance of uncertainty in adolescents: correlations with worry, social anxiety, and depression”. Journal of Nervous and Mental Disease, 2010;

6. Thomas D. Borkovec, „Worry: Thought suppression of emotional processing”. In H. W. Krohne (Ed.). Attention and avoidance, Strategies in coping with aversiveness. Seattle, Toronto: Hogrefe \& Huber, 1993;

7. Nicholas R. Carleton, „The intolerance of uncertainty construct in the context of anxiety disorders: Theoretical and practical perspectives". Expert Review of Neurotherapeutics, 2012;

8. Nicholas R. Carleton. Gorden J. G. Asmundson, „Fearing the unknown: A short version of the Intolerance of Uncertainty Scale". Journal of Anxiety Disorders, 21(1), 2007;

9. Michael W. Eysenck, Colin MacLeod, Andrew Mathews, „Cognitive functioning and anxiety”. Psychological Research, 1987;

10. Siegmund Freud, „Über die Berechtigung, von der Neurasthenie einen bestimmten Symptomkomplex als „Angstneurose“ abzutrennen“. In A. Mitscherlich, A. Richards \& J. Strachey (Hrsg.), Sigmund Freud: Studienausgabe, Frankfurt/M.: S. Fischer. (Erstveröffentlichung 1895), 1971;

11. Thomas Fergus, „Cyberchondria and Intolerance of Uncertainty: Examining When Individuals Experience Health Anxiety in Response to Internet Searches for Medical Information". Cyberpsychology Behavior and Social Networking, 2013;

12. Jürgen Hoyer, Szlvia Helbig, Jürgen Margraf, „Diagnostik der Angststörungen“. Göttingen: Hogrefe, 2005;

13. Jürgen Hoyer, Jürgen Margraf, „Angstdiagnostik - Grundlagen und Testverfahren“. Berlin: Springer, 2003;

14. Caroll E. Izard, „The psychology of emotions”. New York: Plenum, 1991;

15. Heinz Walter Krohne, „Vigilance and cognitive avoidance as concepts in coping research”. In H. W, 1993;

16. Heinz Walter Krohne, „Coping with stress: Dispositions, strategies, and the problem of measurement”. In M. H. Appley \& R. Trumbull (Eds.), Dynamics of stress. Physiological and social perspectives, New York: Plenum, 1986;

17. Heinz Walter Krohne, „Attention and avoidance: Strategies in coping with aversiveness”, Seattle: Hogrefe \& Huber;

18. Peter J. Lang, „The cognitive psychophysiology of emotion: Fear and anxiety”. In A. H. Tuma \&J. Maser (Eds.), Anxiety and the anxiety disorders. Hillsdale: Erlbaum, 1985; 
19. Richard S. Lazarus, „Emotion and adaptation”. London: Oxford University Press, 1991;

20. Burrhus F. Skinner, „Science and human behavior”. Oxford, England: Macmillan, 1953;

21. David Watson, Ronald Friend, „Measurement of social-evaluative anxiety”. Journal of Consulting and Clinical Psychology, 1969;

22. Yo-Tao Xiang, Yuan Yang, Wen Li, Ling Zhang, Qinge Zhang, Teris Cheung, ,Timely mental health care for the 2019 novel coronavirus outbreak is urgently needed". Lancet Psychiatry, 2000. 